\title{
Comparison of numerical simulation and experimental study on indoor air quality of air-conditioned office building in desert climate
}

\author{
A.M. Wahhad ${ }^{1}$, N. M. Adam ${ }^{1}$ and S.M. Sapuan ${ }^{1,2^{*}}$ \\ ${ }^{1}$ Department of Mechanical and Manufacturing Engineering, \\ Universiti Putra Malaysia, 43400 UPM Serdang, Selangor, Malaysia \\ Email: Aliwhaad@yahoo.com; mariah@eng.upm.edu.my \\ 43400 UPM Serdang, Selangor, Malaysia \\ ${ }^{2}$ Laboratory of Biocomposite Technology \\ Institute of Tropical Forestry and Forest Products (INTROP) \\ Universiti Putra Malaysia, 43400 UPM Serdang, Selangor, Malaysia \\ *Email: sapuan@upm.edu.my
}

\begin{abstract}
This paper is a study of the air temperature distribution of an air-conditioned office room equipped with a double-glazed window in a desert climate. The study includes both experimental and theoretical works using a computational fluid dynamics (CFD) simulation program. The experimental results were compared with the CFD program results. The commercial computational fluid dynamics ANSYS CFD V.13.0, solver FLUENT software, and three-dimensional flow finite difference of $k$ - $\varepsilon$ for analysis and validation experimental work were used. The main objective of the study is to evaluate the temperature difference between the outdoor and indoor environments, as well as the distribution of air temperature in the room. The computational results for internal air temperatures of the office ranged from $23^{\circ} \mathrm{C}$ to $26^{\circ} \mathrm{C}$, while the airflow velocity was low at less than $0.3 \mathrm{~m} / \mathrm{s}$. The temperature differences between the indoor and outdoor spaces varied between $9{ }^{\circ} \mathrm{C}$ and $15^{\circ} \mathrm{C}$. Good agreement was achieved between the computed and measured temperature results. The error percentage varied from $0.3 \%$ to $0.8 \%$. The experimental and numerical results showed that well-designed double glazing can reduce the emission of sunshine and heat inside desert buildings, even using the northeastern facade, in sunny climates.
\end{abstract}

Keywords: Double-glazed window; new model office building; desert climate; CFD.

\section{INTRODUCTION}

Improvement of the quality of life in the energy sectors has been helped by recent technologies such as solar, wind, bioenergy, tidal and biomass [1]. Solar energy from solar radiation can be harvested for domestic and industrial uses. However, in certain regions such as in the Middle East, extreme solar radiation may cause discomfort to office building users. Ways to overcome the problem associated with this have been studied, such as by installing double-glazed windows. An indoor air quality study is carried out to obtain the maximum advantages of the window. The window glazing is the weakest spot in an office's barrier against heat, given the heat transfer compared with the solid exterior walls during solar radiation and the difference in temperature between the internal and the external passages of a building. Double-glazed windows are the most widely used windows in modern buildings and they are sufficient to improve energy efficiency 
through the use of low-emission coatings to reduce heat radiation losses. The desert climate is characterized by the most extreme climatic conditions sometimes including high air temperature, high solar radiation, low rainfall, low humidity, and sandstorms. Direct radiation falling on and through the transparent surfaces of a building contributes a disproportionate amount of energy to the heat balance of the building [2]. The purpose of most air-conditioning systems is to provide comfort and the best quality indoor air, particularly in desert regions where high temperatures, low humidity, and occasional sandstorms occur. Windows are often among the largest sources of unwanted heat gain in the desert's summer climate. Large double-glazed windows have been installed as part of the modern office design in the desert area.

Computational fluid dynamics (CFD) has been widely used in order to gain insight into this issue, but the choice of models suitable for radiation, convection and the effects of turbulence remains a major challenge. Over the past few decades, computational fluid dynamics has become a useful tool for designers to investigate the circumstances of the internal and external environment in building designs. The CFD technique has been successfully applied in building design, enabling designers to analyse the flow pattern of the air-conditioning system within a short period of time, a task that was previously impossible in experimental and theoretical methods [3]. Moreover, CFD helps determine the actual distribution of air flow, temperature, and humidity in the entire domain, which is challenging to obtain from experiments because of time and cost factors. Unfortunately, no universal model can represent the full flow pattern of an air-conditioning system [4]. Baker, Kelso [5] evaluated the thermal comfort conditions of an air-conditioned lecture theatre using measurement via CFD modelling.

Simulation, prediction and evaluation have become the issues of modern natural ventilation, air-conditioning engineering research and the design of the indoor and outdoor air environment. These can be scientific and effective by using CFD numerical prediction, simulation and evaluation, and thus taken more seriously. Cheong, Djunaedy [6] used PHOENICS to run a 3D simulation for an indoor environment. Suárez, Gutiérrez [7] presented a three-dimensional numerical simulation of the airflow inside the glazing gallery. This was included in the results, where the behaviour was closely linked to the weather conditions (irradiation and outdoor temperature); the higher the degree of radiation and outdoor temperature values, the more energy can be collected in the gallery. Carlos, Corvacho [8] presented a mathematical model based on heat transfer expressions for a ventilated double window to predict the thermal performance of design and parameter conditions. The results obtained that the energy of the delivered air is influenced by the difference between the indoor and outdoor temperature, by incident solar radiation and the airflow rate. Ismail, Salinas [9] investigated three types of windows and numerically simulated them for hot climates: a single-glazed window, a doubleglazed window filled with absorbing gases and a ventilated double-glazed window. The numerical simulations were realized with three mixtures of gases: a strongly absorbing gas mixture, an intermediate absorbing gas mixture and a transparent-to-infrared radiation mixture. The double-glazed window filled with absorbing gas and absorbing glass sheets was the most effective. Pal et al. [10] developed mathematical models to simulate the window plane solar radiation and the corresponding glazing surface temperature, with the aim of validating the measured values. They predicted the thermal performance of the building interior due to the impact of solar radiation. Yongson, Badruddin [11] analysed the temperature and velocity distribution over various virtual planes for different locations of the air-conditioner blower to achieve the maximum comfort for the occupants. $K-\varepsilon$ and Reynolds stress models for turbulence flow were used for the analysis. The simulation 
with the Reynolds stress model took longer than the $k$ - $\varepsilon$ model, but the mesh spacing independency seemed to be more significant. Al-Sanea, Zedan [12] studied air flow and thermal characteristics in air-conditioned rooms under conditions of turbulent mixed convection. Air velocity and temperature distributions were determined by a CFD model and compared with experimental work. Several experimental studies were conducted to verify the expected accuracy rates of the thermal environment numerical simulation in the indoor CFD use. The analysis proved the validity of the thermal environment in the indoor model based on turbulent flow, such as the $k-\varepsilon$ model, standard, to be fairly accurate [13]. The measurements of thermal air velocity and temperature distributions obtained in the test room were compared on a full scale with the 2-D finite-volume method $(k-\varepsilon)$ model [14]. The numerical prediction of interactions between the indoor and outdoor thermal environments was the focus of a number of previous studies [15-21]. The main objective of this study is to investigate the numerical method and the results were validated using experimental data for the temperature difference between the outdoor and indoor environment conditions, as well as the air temperature distributions in the new model in an office located in the desert.

\section{METHODS AND MATERIALS}

\section{Physical Model and Assumption}

In this study, the building chosen consists of four storeys. The building is an airconditioned administrative office centre built in 2002 as part of Libya's regional development, as shown in Figure 1. The building is located in Hoon City, province of Al Jufrah, Southern Libya, at lat. $29^{\circ} 7^{\prime} \mathrm{N}$ and long. $15^{\circ} 56^{\prime} \mathrm{E}, 300 \mathrm{~km}$ south of the Mediterranean coast.

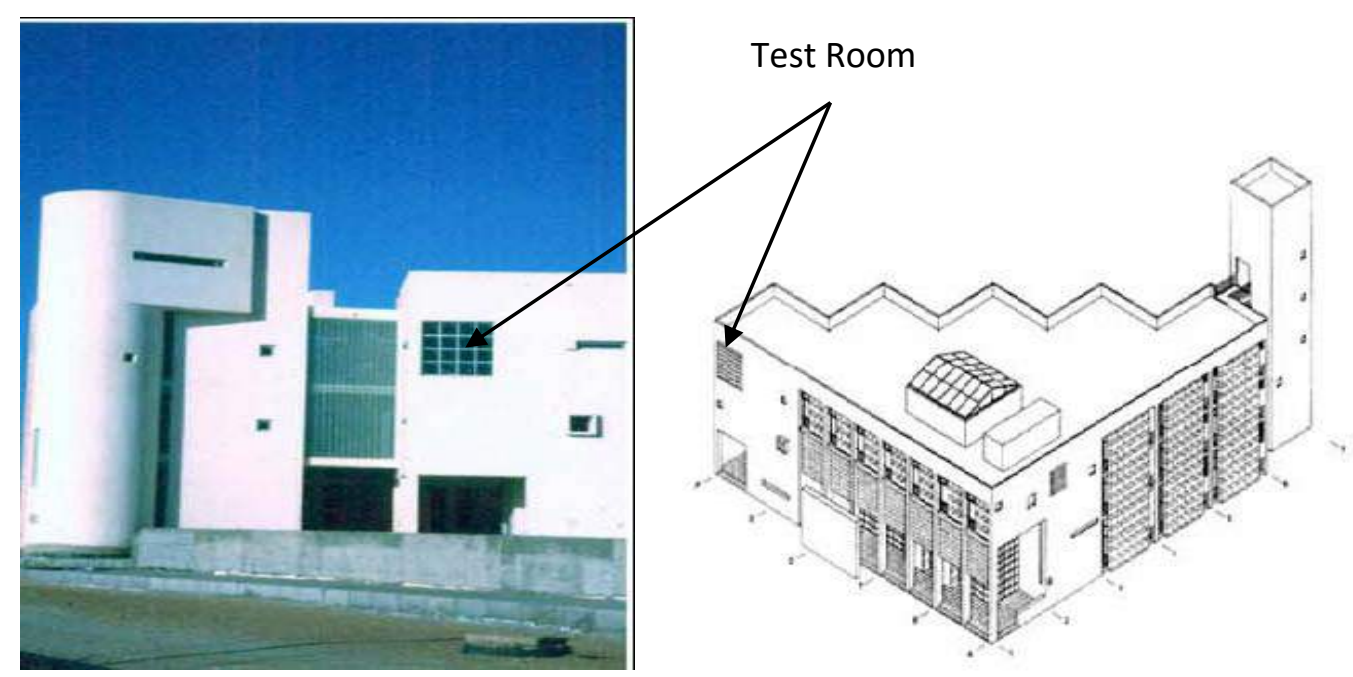

Figure 1. The buildings in Hoon, Libya (Source: Al-Jufrah Administration).

The testing office is located on the third floor of the four-storey reinforced concrete building. The office is $4.5 \mathrm{~m}$ long $\times 3.80 \mathrm{~m}$ wide $\times 3.20 \mathrm{~m}$ high, as shown in Figure 2. A double-glazed window in the northern facade of the building is found. The window has the following dimensions: $2.36 \mathrm{~m}$ length $\times 2.36 \mathrm{~m}$ width $\times 6 \mathrm{~mm}$ thickness for each layer. The space between the two surfaces is $20 \mathrm{~mm}$. The east and north walls are exterior walls, and the west and south walls are interior. The exterior walls are made 
of reinforced concrete. These double walls are each $20 \mathrm{~cm}$ thick. The space between the two walls is filled with polyurethane foam, an insulating material with $5 \mathrm{~cm}$ thickness. The office floor is covered with a marble material. The internal and external faces of the walls are painted white. An air-conditioner blower has been installed asymmetrically in the office and is positioned on the southern wall. The distance between the air-conditioner and the ceiling and ground is 0.15 and $3 \mathrm{~m}$, respectively. The room is illuminated by three sets of twin double-batten fluorescent lights. The present study aims to evaluate the internal distribution of temperatures starting from the window up to the centre of the room. This study also intends to evaluate the temperature difference between the outdoor and indoor environments of the office.

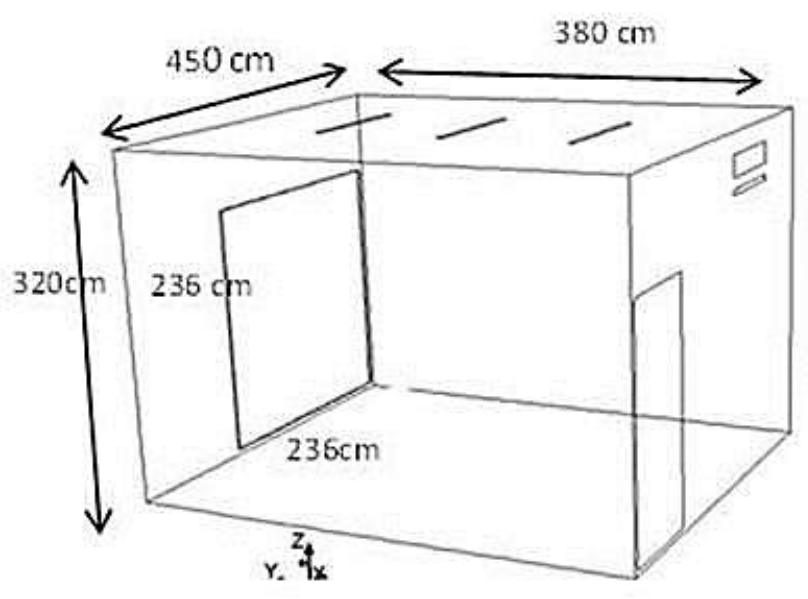

Figure 2. Office room model sketch.

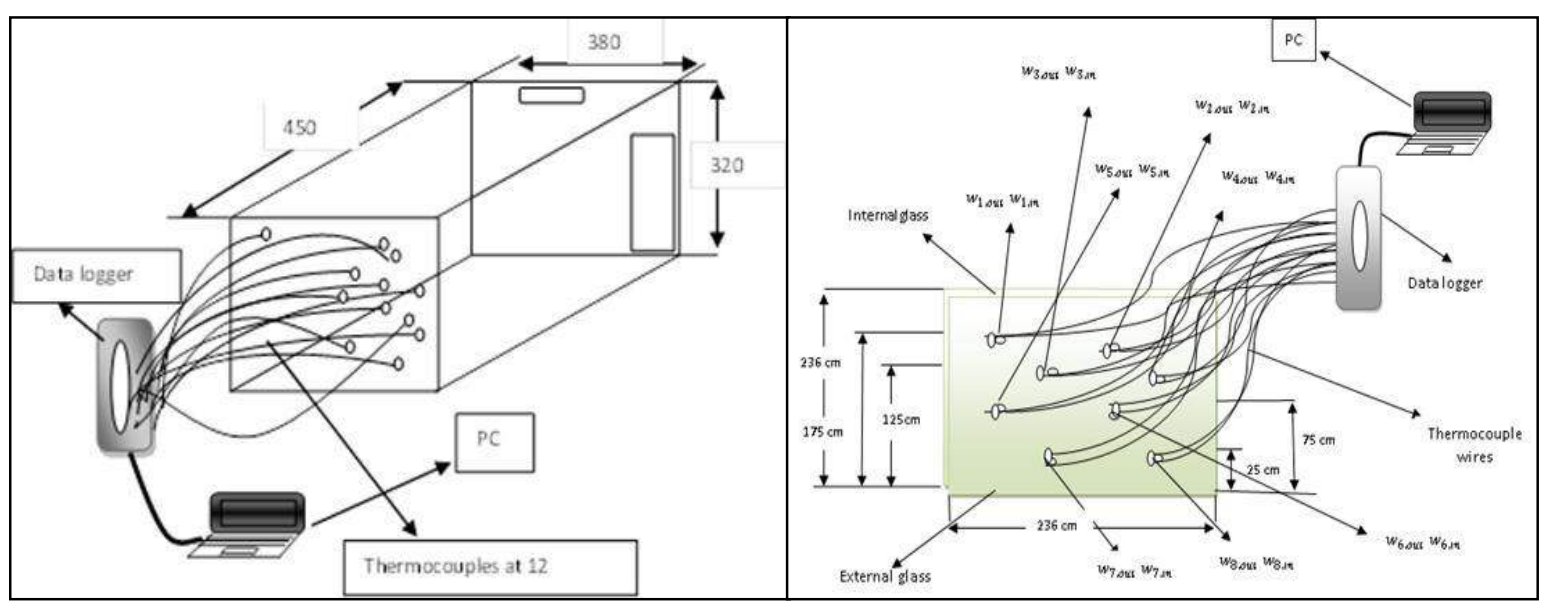

Figure 3. Thermocouples locations in the office and above the external and internal surfaces of the double-glazed window.

\section{Experimental Setup}

The air conditioner was operated from 8:30 to 18:00. The air-conditioned temperature was controlled between $16^{\circ} \mathrm{C}$ and $18{ }^{\circ} \mathrm{C}$. The temperature stability and equilibrium was established gradually after about half an hour with the air conditioner switched on. The office room temperature reached $23.4{ }^{\circ} \mathrm{C}$ around 9:00 am. After two hours the outside air temperature reached $38{ }^{\circ} \mathrm{C}$, and the highest value was obtained at around 15:00. The 
experimental measurements were conducted from July to August 2009. The continuous data collection was carried out from 09:00 to 18:00. A total of 12 thermocouples were placed at different positions inside the room to measure the air and wall temperatures. In this study thermocouple wires type (T) were selected to measure the temperature within the range of $-40{ }^{\circ} \mathrm{C}$ to $1200{ }^{\circ} \mathrm{C}$. Thermocouple wires are flexible, reliable, easy to use and accepted widely for field measurements. The outdoor measurements and indoor air temperature were measured at the centre of the office, $2 \mathrm{~m}$ from the window [22]. A data acquisition system of programmable data loggers (D80 and 85) was used with online transfer, as shown in Figure 3. The arrangements for temperature measurement are as follows: eight thermocouples were placed at eight different positions on the inner surface to measure the surface inner temperature. An additional eight thermocouples were placed on the outer surface to measure the surface outer temperature.

\section{CFD Modelling and Simulation}

The ANSYS CFD V.13.0 solver FLUENT was used to simulate the temperature distribution and air flow in the air-conditioned office. The flow simulation was conducted based on the standard $k-\varepsilon$ model $[22,23]$. The flow was assumed to be three-dimensional, steady-state, incompressible, and turbulent. Convective heat transfer at the walls and windows was calculated, and the air was considered as an ideal gas. The heat transfer through the large window was computed using the given outside air temperature as reference, assuming a steady constant heat transfer, and neglecting heat accumulation. The model was assumed to be a simple office exposed to sun rays. Boundaries should have both convection and radiation heat transfer through the window. To analyse the radiation heat transfer of mutual reflection, the Monte Carlo method and Gebhart absorption coefficient method were used to calculate the factor display. The empirical equation for the distribution along the beam keeps the multiple Monte Carlo integration and the effects of temperature distributions in the radiation system and allows any model for the absorption of gases used [24]. Application of the Monte Carlo method is discussed by [25-28]. The window was set to have emissivity for outer (low-e) and inner layers (clear glass). Table 1 shows the volume condition properties of the materials.

Table 1. Volume condition properties of materials [29].

\begin{tabular}{llll}
\hline Materials & Air & Glass & Aluminium \\
\hline Density $\left(\mathrm{kg} / \mathrm{m}^{3}\right)$ & 1.225 & 2800 & 2719 \\
Specific heat $(\mathrm{J} / \mathrm{kg} \mathrm{1C)}$ & 1006.43 & 750 & 871 \\
Thermal conductivity (W/m 1C) & 0.0242 & 0.7 & 177 \\
Inner clear glass 6 mm & & 0.89 & - \\
Outer (low-e), glazed (6 mm) & - & 0.022 & - \\
\hline
\end{tabular}

The CFD model boundary conditions were provided by the experimental measurements of the wall temperatures. Figure 4 and Table 2 show the surface boundary conditions used in the CFD simulation based on the experimental work. The summary of indoor loads in the testing office is reported in Table 2 . The volume conditioner properties of the blocks are shown in Table 3. 


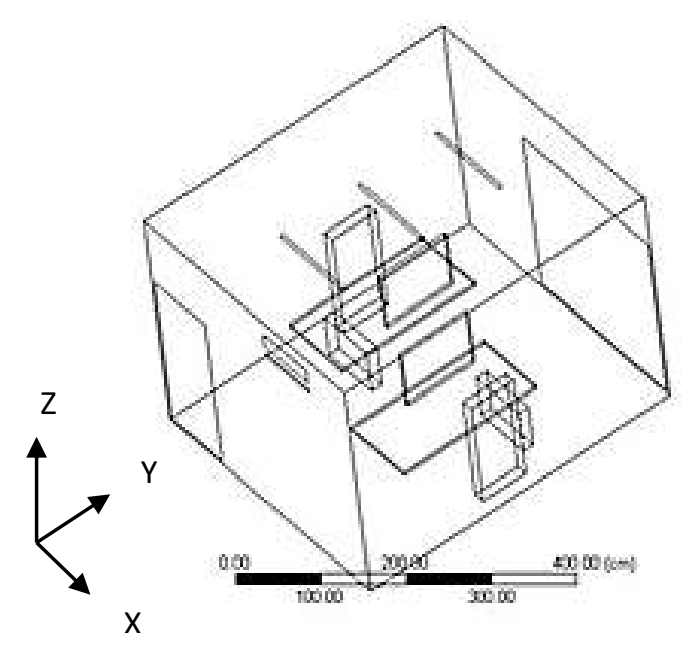

Figure 4. Surface boundary condition of test office.

Table 2. Boundary conditions of office.

\begin{tabular}{llll}
\hline Boundary & Count & Model type & Parameters value \\
\hline Door & 1 & wall-close & - \\
Tables and chairs & 2 & wall & - \\
People & 2 & people & $2 \times 80 \mathrm{w} / \mathrm{m}^{2}$ \\
Monitors & 2 & wall & $2 \times 10 \mathrm{w} / \mathrm{m}^{2}$ \\
Computers & 2 & blocks & $2 \times 75 \mathrm{w} / \mathrm{m}^{2}$ \\
Fluorescent lamps (off) & 3 & blocks & $3 \times 120 \mathrm{w} / \mathrm{m}^{2}$ \\
Inner clean glazed window & & wall & $300 \mathrm{~K}$ \\
Outer glazed window & 1 & wall & $305 \mathrm{~K}$ \\
Air outlet & 1 & open & $\mathrm{T}=295 \mathrm{~K}$ \\
Air inlet & 1 & vent & $\mathrm{T}=296 \mathrm{~K}$ \\
Façade wall & - & wall & $\mathrm{T}=296.3 \mathrm{~K}$ \\
West side wall & - & wall & $\mathrm{T}=294.8 \mathrm{~K}$ \\
East side wall & & wall & $300 \mathrm{~K}$ \\
South side wall & - & wall & $293.8{ }^{\circ} \mathrm{C}$ \\
Ceiling side wall & - & wall & neglected \\
Ground side wall & - & wall & neglected
\end{tabular}

Table 3. Volume conditioner setting for properties of blocks.

\begin{tabular}{ll}
\hline Code & Description \\
\hline Turbulence model & Standard $k$ - $\varepsilon$ model \\
Algorithm & Steady state (SIMPLER) \\
Analysed area & $4.5 \mathrm{~m} \times 3.80 \mathrm{~m} \times 3.20 \mathrm{~m} \&$ glass window \\
& $2.36 \mathrm{~m} \times 2.36 \mathrm{~m} \times 0.32 \mathrm{~m}$ \\
Convection term scheme & Implementing a QUICK convection scheme \\
Wall boundary condition & Standard log-low, adiabatic \\
Cells of mesh & 806329 \\
\hline
\end{tabular}


The hexahedral cell was chosen because of its homogeneity with the office model. The three types of grid spacing are $15 \mathrm{~cm}$ (coarse), $10 \mathrm{~cm}$ (medium), and $7.5 \mathrm{~cm}$ (fine). The non-uniform grids were used in consideration of the positions with large gradients of solution variables (air velocity and temperature). Grid refinement occurred on the window surface in the presence of the heat source. Figure 5 shows the grid mesh generation.

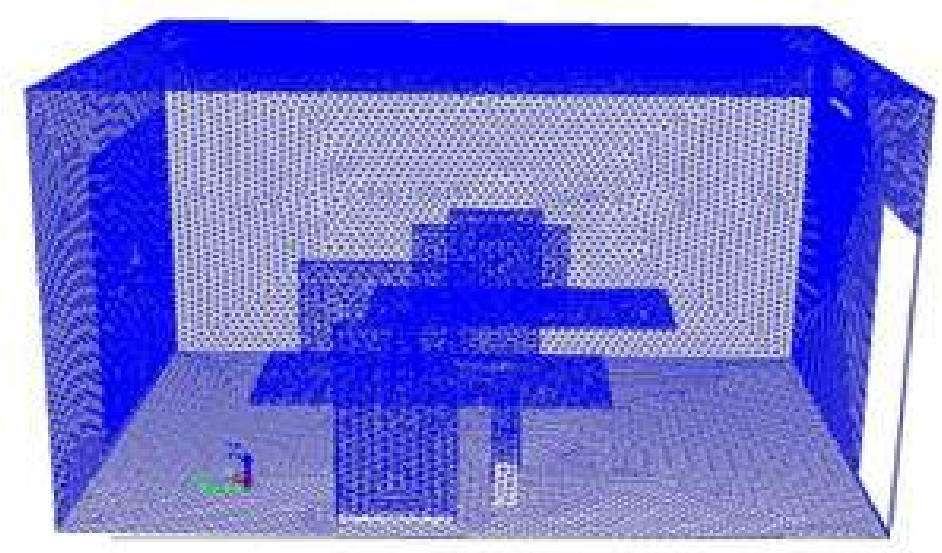

Figure 5. Grid mesh generation.

\section{Governing Equations}

Three groups of basic equations are derived from the three basic laws of conservation. Mass, momentum, and energy conservation respectively result in the continuity, NavierStokes, and energy equations. Since turbulent flow [30] occurs in an air-conditioned room, the $k-\varepsilon$ and Reynolds stress viscous models have been chosen for investigation. The standard $k-\varepsilon$ model is a semi-empirical model based on model transport equations for the turbulent kinetic energy $(k)$ and its dissipation rate $(\varepsilon)$. The transport equation of $k$ is derived from the exact equation, and the transport equation of $\varepsilon$ is obtained using physical reasoning and bears a minimal resemblance to its mathematically exact counterpart. Based on the above assumptions, the energy, momentum and continuity equations for this study can be written as stated by [31]:

$$
\begin{gathered}
\frac{\partial u}{\partial x}+\frac{\partial v}{\partial y}+\frac{\partial w}{\partial z}=0 \\
\frac{\partial \rho}{\partial t}+\frac{\partial}{\partial x}(\rho U)+\frac{\partial}{\partial y}(\rho V)+\frac{\partial}{\partial z}(\rho W)=0
\end{gathered}
$$

Conservation of momentum (Navier-Stokes equations):

Applying a law of conservation of momentum in the $\mathrm{x}, \mathrm{y}$ and $\mathrm{z}$ directions, the following equations are obtained:

The X-momentum equation:

$$
\rho\left(u \frac{\partial u}{\partial x}+v \frac{\partial u}{\partial y}+w \frac{\partial u}{\partial z}\right)=-\frac{d p}{d x}+\mu\left(\frac{\partial^{2} u}{\partial x^{2}}+\frac{\partial^{2} u}{\partial y^{2}}+\frac{\partial^{2} u}{\partial z^{2}}\right)
$$

The Y-momentum equation:

$$
\rho\left(u \frac{\partial v}{\partial x}+v \frac{\partial v}{\partial y}+w \frac{\partial v}{\partial z}\right)=-\frac{d p}{d y}+\mu\left(\frac{\partial^{2} v}{\partial x^{2}}+\frac{\partial^{2} v}{\partial y^{2}}+\frac{\partial^{2} v}{\partial z^{2}}\right)
$$


The Z-momentum equation:

$$
\rho\left(u \frac{\partial w}{\partial x}+v \frac{\partial w}{\partial y}+w \frac{\partial w}{\partial z}\right)=-\frac{d p}{d x}+\mu\left(\frac{\partial^{2} w}{\partial x^{2}}+\frac{\partial^{2} w}{\partial y^{2}}+\frac{\partial^{2} w}{\partial z^{2}}\right)
$$

The Energy Equation:

The conservation of thermal energy in the volume control, $\mathrm{dx}, \mathrm{dy}$, and $\mathrm{dz}$, states that the net increase in internal energy in the volume control is equal to the net flow of energy through convection in addition to the net inflow by thermal and mass diffusion. The energy equation per unit volume is:

$$
\frac{\partial}{\partial t}(\rho T)+\frac{\partial}{\partial x}(\rho U T)+\frac{\partial}{\partial y}(\rho V T)+\frac{\partial}{\partial z}(\rho W T)=\frac{\partial}{\partial x}\left(\Gamma \frac{\partial T}{\partial x}\right)+\frac{\partial}{\partial y}\left(\Gamma \frac{\partial T}{\partial y}\right)+\frac{\partial}{\partial z}\left(\Gamma \frac{\partial T}{\partial z}\right)
$$

where $\mathrm{P}=$ effective density; $\mathrm{c}_{p}=$ heat capacity; $\mu=$ dynamic viscosity; $k=$ thermal conductivity; $T=$ temperature of coolant $\left({ }^{\circ} \mathrm{C}\right) ; \Gamma=$ the diffusion coefficient, which is $\mu$ $/ \sigma$, and $\sigma=\mu \mathrm{c} p / \lambda$ is the Prandtl number for a fluid.

Initial and boundary conditions must be specified around the system boundary (domain) to solve these equations. The equations are highly nonlinear and cannot be solved by explicit, closed-form analytical methods. The numerical finite volume method has been used to solve these equations. Upon solving them, the values of the dependent variables are known at the nodal points. The values of several constants in the differential equations are empirical constants at $C_{1 \varepsilon}=1: 44$ and $C_{2 \varepsilon}=1.92 ; \sigma_{k}$ and $\sigma_{\varepsilon}$ are turbulent Prandtl numbers for $k$ and $\varepsilon$, where $\sigma_{\mathrm{k}}=1.0$ and $\sigma_{\varepsilon}=1.3$. All standard values were used for simulation.

\section{Code Validation}

The codes validations of this study depend on two papers, two of which are numerical simulations. Manz [32] use PHOENICS to simulate the 3D numerical simulation for the office environment inside a thermal air-conditioned room in the summer. The velocity and air temperature field were simulated inside the air-conditioned room and the numerical simulation showed good agreement with the experimental data through analysis and comparison, while the maximum accuracy error between the results of the measurements and simulations was $8.23 \%$. Hamza [33] analysed the temperature and velocity distribution over various virtual planes for different locations of the airconditioner blower to achieve the maximum comfort for the occupant. $K$ - $\varepsilon$ and Reynolds stress models for turbulence flow were used for the analysis.

\section{RESULTS AND DISCUSSION}

\section{Temperature Distribution within Office}

Figure 5 shows the average temperature distribution in the office using the CFD simulation. Temperature stratification, which covered almost the entire office, and average temperatures, were determined to be $296 \mathrm{~K}$ to $299 \mathrm{~K}$ within the office. The temperature difference between the outdoor and indoor environments was approximately $6 \mathrm{~K}$ to $13 \mathrm{~K}$. The temperature difference between the ceiling and ground was approximately $1.4 \mathrm{~K}$. The temperature of the inner surface of the window was relatively low, or roughly $299.8 \mathrm{~K}$ to $302.5 \mathrm{~K}$. The temperature of the outer surface of the window was approximately $302 \mathrm{~K}$ to $311 \mathrm{~K}$. The temperature difference between the outer and 
inner surfaces therefore varied from $9 \mathrm{~K}$ to $15 \mathrm{~K}$. These values are according to the values reported in the literature. Howell [22] presented values ranging from 10 to $15^{\circ} \mathrm{C}$ for three buildings with double-glazed façades that were monitored in summer, while Larsen et al. [34] measured a difference of $8-10{ }^{\circ} \mathrm{C}$ between the indoor and outdoor temperatures, for a double-glazed façade in the summer in the Northwest of Libya.

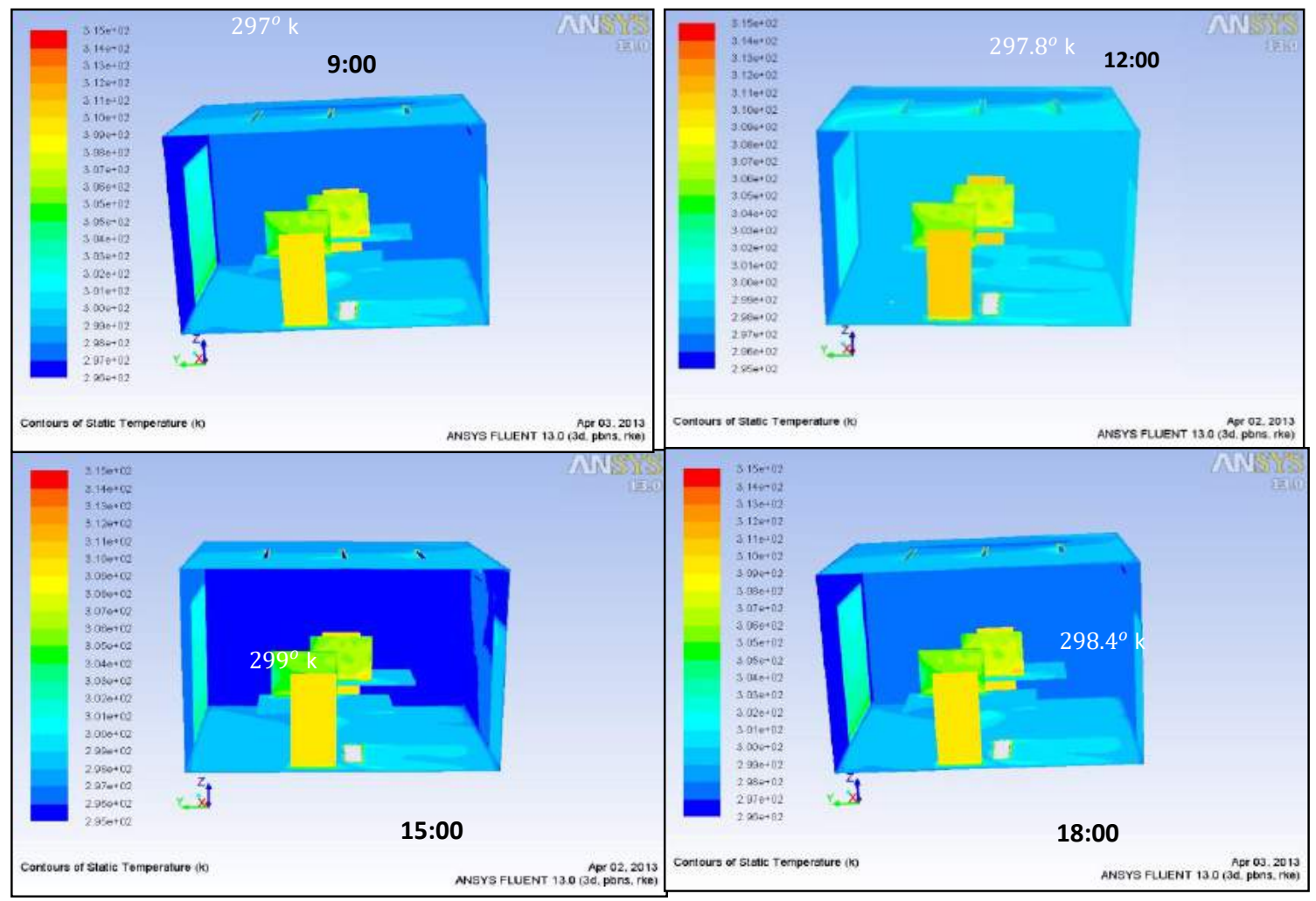

Figure 6. Average temperatures by CFD (9:00, 12:00, 15:00 and 18:00) (15.8.2009).

Table 4. Temperature distribution for distance into test office.

\begin{tabular}{ccccc}
\hline Time & $0.5 \mathrm{~m}$ & $1 \mathrm{~m}$ & $1.5 \mathrm{~m}$ & $2 \mathrm{~m}$ \\
\hline $9: 00$ & 25.9 & 26 & 26 & 26.5 \\
$12: 00$ & 24.6 & 24.7 & 24.2 & 24.8 \\
$15: 00$ & 25.9 & 26 & 26 & 26.5 \\
$18: 00$ & 25.6 & 25.7 & 25.8 & 26.2 \\
\hline
\end{tabular}

Figure 6 shows the temperature stratification distribution inside the office with distances from the surface of the glass up to $2 \mathrm{~m}$ further into the middle of the office at various times $(9: 00,12: 00,15: 00$ and 18:00). The temperatures were almost identical with only a few differences. Table 4 shows the temperature distribution at different positions $(0.5 \mathrm{~m}, 1 \mathrm{~m}, 1.5 \mathrm{~m}$, and $2 \mathrm{~m})$ from the window during the cooling period. The temperature difference between distances 0.5 and $2 \mathrm{~m}$ has a maximum value of approximately $2 \mathrm{~K}$ at $12 \mathrm{am}$. Thermal comfort of the occupied condition was from $0.5 \mathrm{~m}$ to $1.5 \mathrm{~m}$ from the window due to the cooled air from the cooling panel of the air conditioner. In addition, the air temperature was lower near the glass window and slightly higher at a distance of $1 \mathrm{~m}$ from the glass window. 

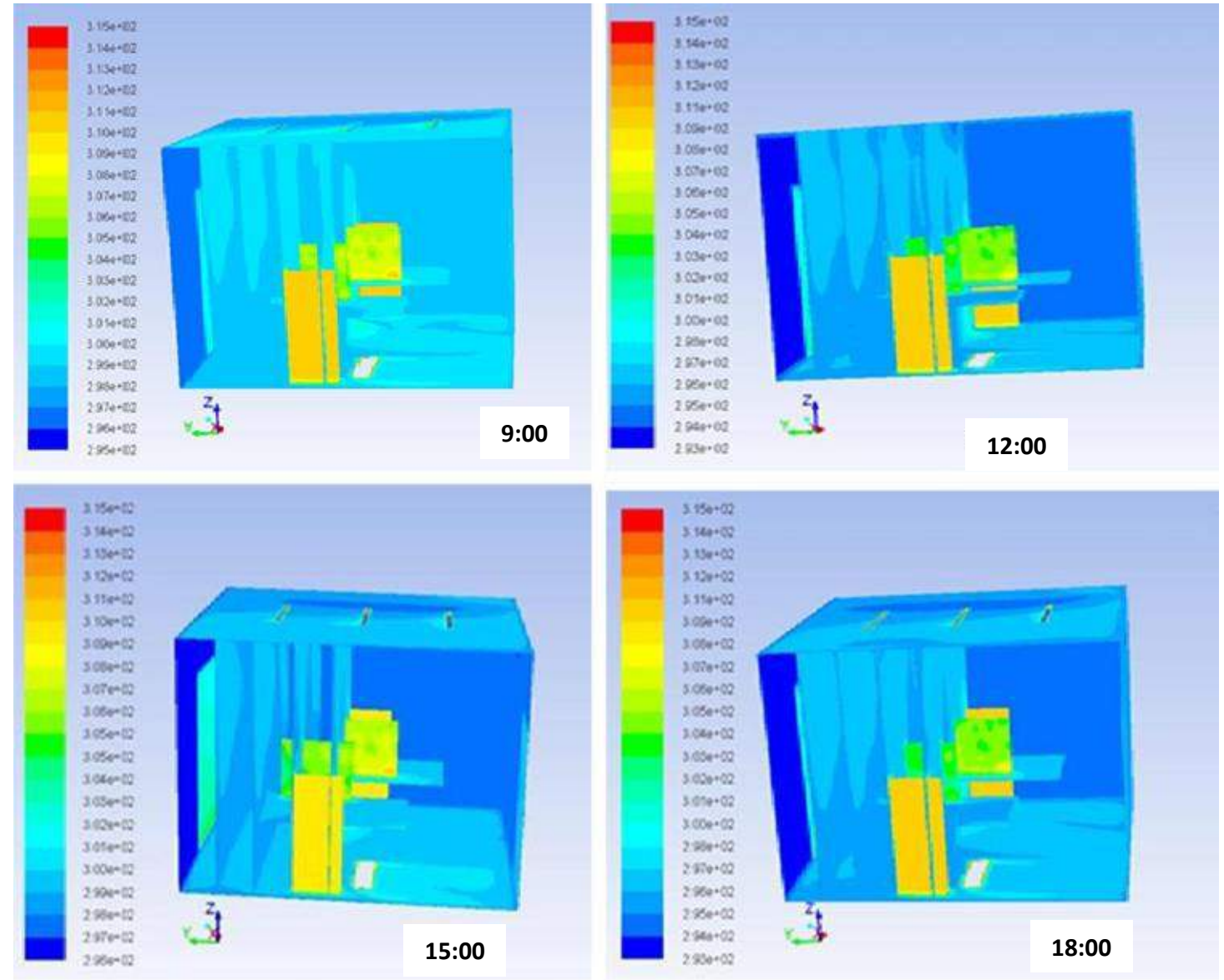

Figure 7. Temperature distribution inside the room at different times.

\section{Airflow Distribution within Office}

Figure 8 shows the distribution of the air flow according to estimates by CFD simulation inside the whole room. It was observed that the airflow near the air conditioner was 1.1 to $1.3 \mathrm{~m} / \mathrm{s}$, while a downward flow was observed close to the windows due to emitted heat, and the average airflow velocity was low at less than $0.3 \mathrm{~m} / \mathrm{s}$. The average air velocities inside the room ranged from $0.1 \mathrm{~m} / \mathrm{s}$ to $0.3 \mathrm{~m} / \mathrm{s}$ when the average air temperatures were $296 \mathrm{~K}$ to $299 \mathrm{~K}$, as shown in Figure 6. The region near the occupants would feel cold due to the high density of occupants, and the distance from the window is $1 \mathrm{~m}$ to avoid the heat emitted from the window.

\section{Experimental Results Analysis}

The experimental results were compared with the theoretical CFD simulation to determine how far they matched. Figure 9 compares the average temperature inside the room from both approaches. Significant agreement was achieved between the theoretical and experimental values. The average relative error varied from $0.3 \%$ to $0.7 \%$, which was acceptable for engineering applications. Larsen et al. [34] presented an average error of $13 \%$ which, though not alarmingly large, is clearly larger than the average experimental confidence indicator. 

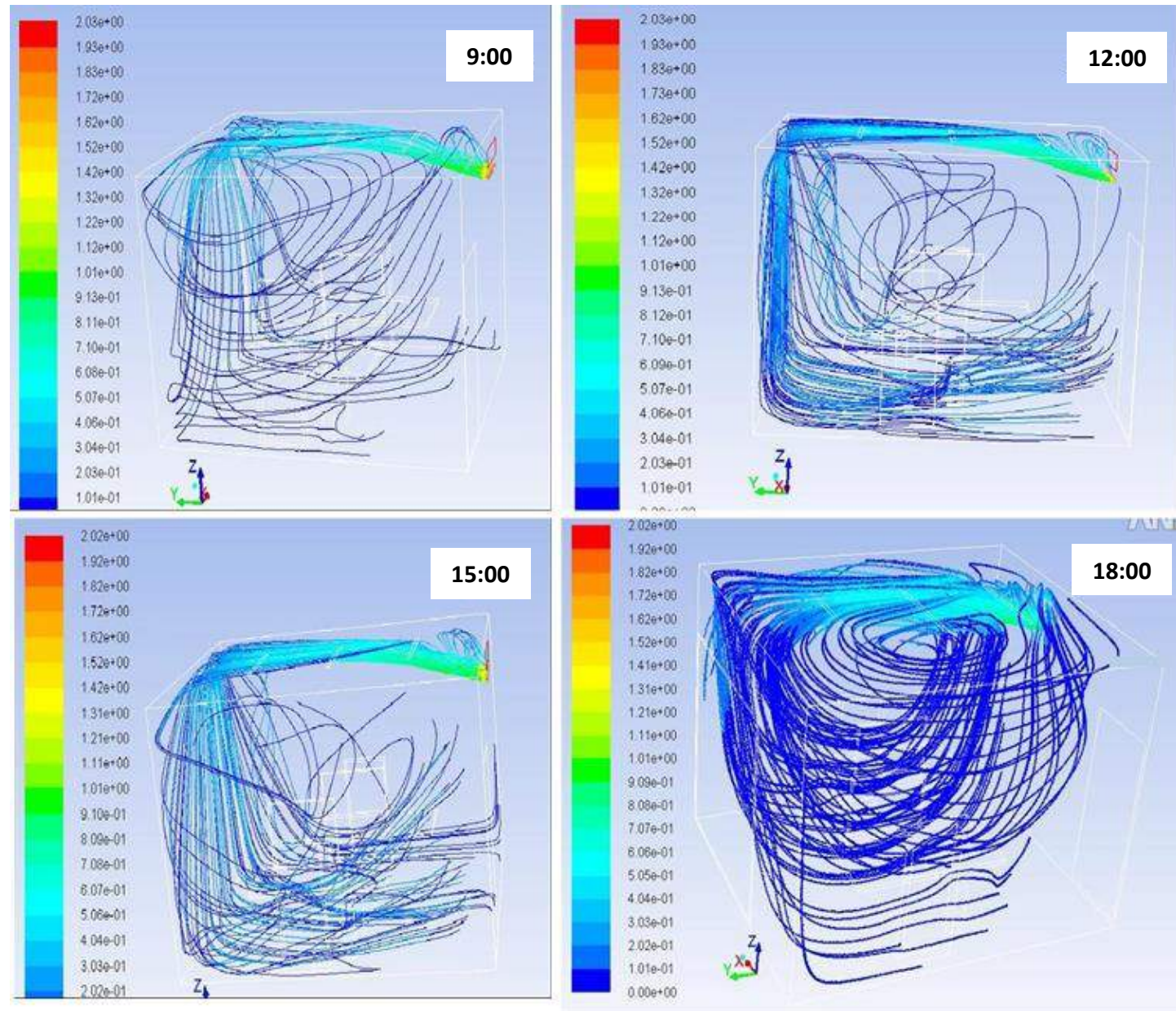

Figure 8 . Air velocity distribution inside the room at different times.

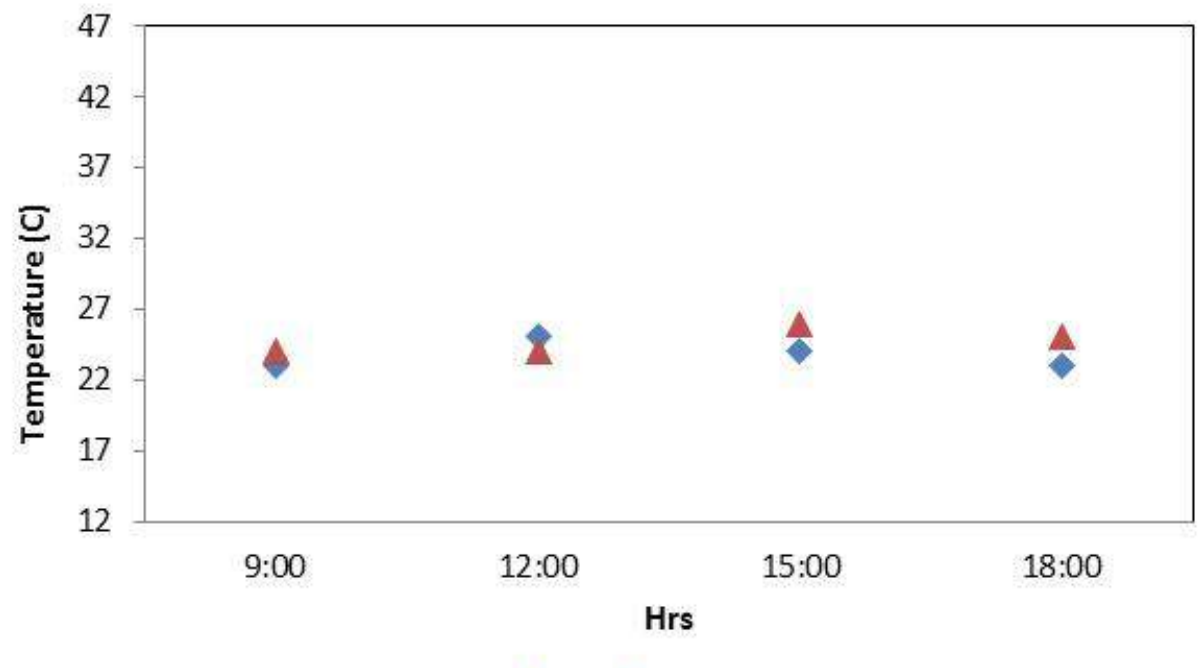

$\Delta$ EXP. $\triangle$ CFD

Figure 9. Comparison of variation of internal temperature with time for experimental and CFD results. 


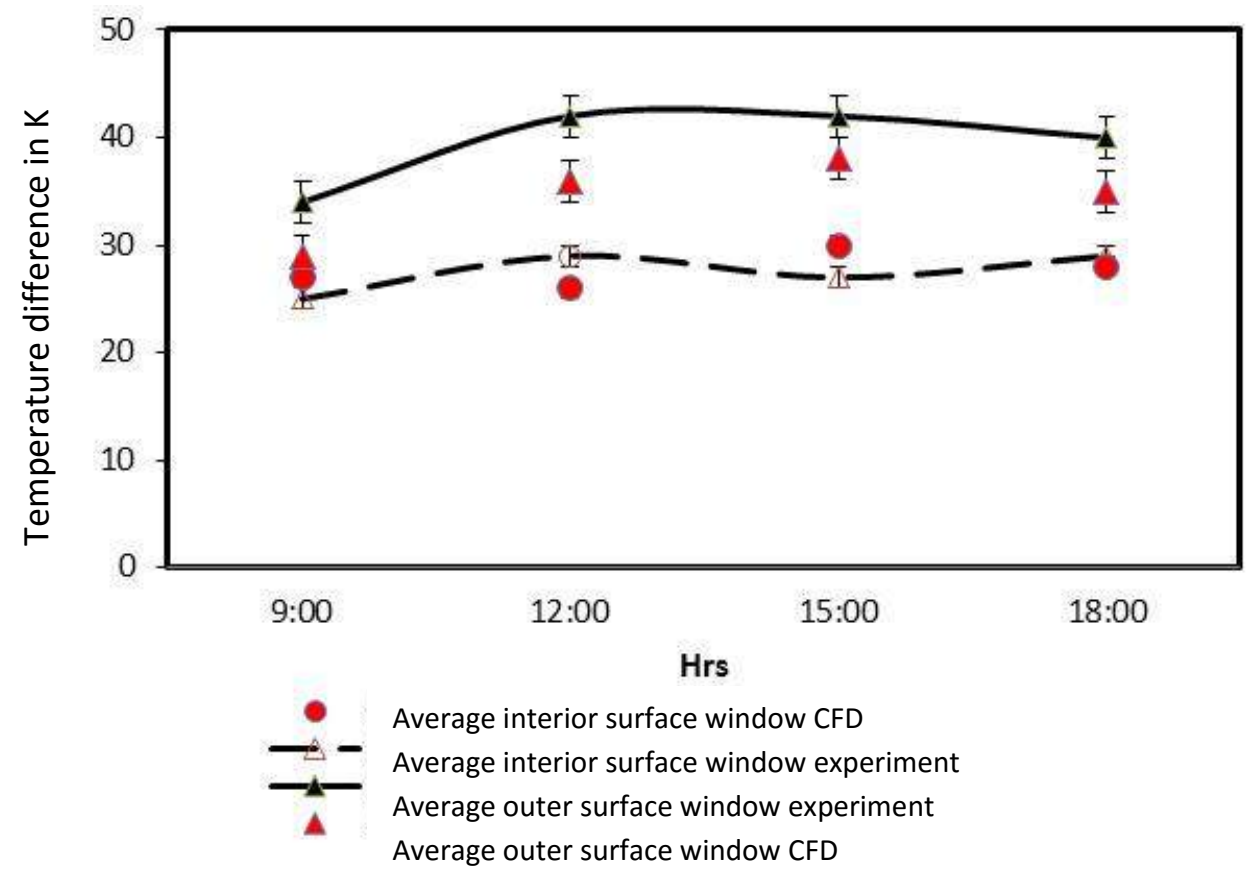

Figure 10. Comparison of experimental and CFD results of inner and outer glass surfaces.

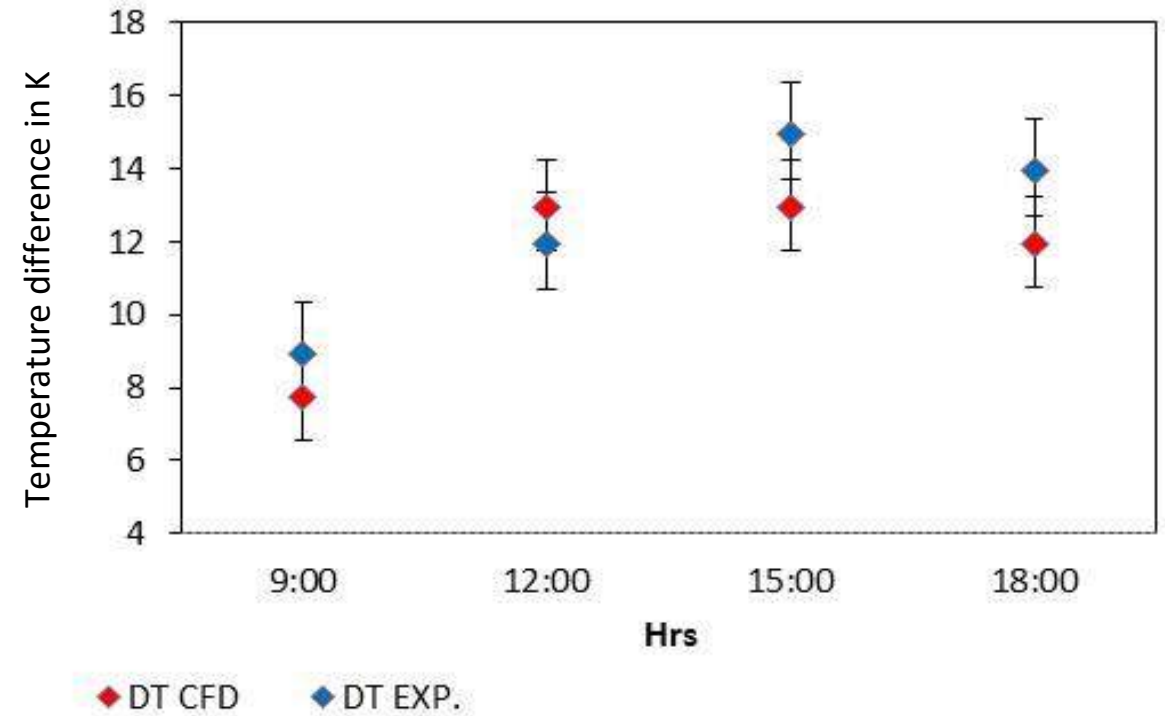

Figure 11. Comparison of experimental and CFD results of temperature differences between outdoor and indoor environments of office

Figure 10 compares the results of the average air temperature profiles of the internal and external window surfaces for both the experimental and theoretical CFD simulation procedures. At 12:00 and 15:00 the highest temperatures recorded were 315 $\mathrm{K}$ on the outer surface and $300 \mathrm{~K}$ on the inner surface. The highest temperatures were recorded at 12:00 and 15:00, reaching $340 \mathrm{~K}$ on the outer surface and $325 \mathrm{~K}$ on the inner surface. The predicted temperature difference between the internal and external surfaces was $10 \mathrm{~K}$ as compared with standard data from CIBSE [34], and it is seen that the 
predicted values agree well with the standard values. Figure 11 compares the difference in temperature between the outdoor and indoor environments for the experimental and theoretical CFD simulation procedures. It may be that at 12 noon only one mark appeared due to the coincidence of the experimental result with the theoretical result i.e. overlapping occurred. The highest temperature difference was found at 15:00. Manz [32] Hamza [33] and Larsen et al. [34] recommended the use of glazing with high properties such as low-e coating, for glazed areas of the offices with a double-glazed window. The double-glazed window minimizes heat in the cavity and low-e reduces the radiative heat from the double-glazed window, while [34] showed that a well-designed double-glazed window can reduce the summer energy consumption of buildings, even with a west-facing double-glazed facade in sunny climates.

\section{CONCLUSIONS}

Air velocity and air temperature measurements are simulated and analysed by numerical simulation for the indoor environment in an air-conditioned office in a desert country. This study was based on a pilot study fully supported by the analysis of the air velocity distribution and temperature distribution within the office. The CFD-simulation-based model is used to predict air temperature and air velocity distributions in a model office room. From the comparison of the CFD simulation with field measurements and results using the realizable $k-\varepsilon$, the main results and recommendations are as summarised below:

(1) The difference between the internal and external temperatures is almost constant during the day and varies from $9^{\circ} \mathrm{C}$ to $14^{\circ} \mathrm{C}$.

(2) The internal temperature decreases with increase of the distance from the window.

(3) The CFD program has the same temperature profile trend as that achieved experimentally.

(4) The airflow velocity inside the test office was low at less than $0.3 \mathrm{~m} / \mathrm{s}$.

(5) The CFD program has good agreement with the experimental results. The maximum percentage error is $4.4 \%$.

(6) The maximum temperature difference is $15 \mathrm{~K}$ obtained at 15:00. The minimum temperature difference is $8 \mathrm{~K}$ at 09:00.

(7) The experimental and numerical results showed that well-designed double glazing can reduce the emission of sunshine and heat into desert buildings, even using a northeastern facade, in sunny climates.

\section{ACKNOWLEDGMENTS}

The authors are grateful to Faculty of Technical Engineering, Hoon, Libya for thier assistance in data collection. Sincere appreciation is also extended to the Department of Mechanical and Manufacturing Engineering, Universiti Putra Malaysia for laboratory facilities. The authors also wish to thank the Universiti Putra Malaysia for the support granted to this study.

\section{REFERENCES}

[1] Masjuki H, Sapuan SM. Palm oil methyl esters as lubricant additive in a small diesel engine. Journal of the American Oil Chemists' Society. 1995;72:609-12. 
[2] Handbook A. Fundamentals. American Society of Heating, Refrigerating and Air Conditioning Engineers, Atlanta. 2001;111.

[3] Pereira FO, Sharples S. The development of a device for measuring solar heat gain and shading coefficients of windows in scale models. Energy and buildings. 1991;17:271-81.

[4] Anderson J. JD, Computational Fluid Dynamics. McGraw-Hill International Editions, New York; 1995.

[5] Baker A, Kelso RM, Gordon EB, Roy S, Schaub EG. Computational fluid dynamics: A two-edged sword. ASHRAE journal. 1997;39:51.

[6] Cheong K, Djunaedy E, Chua Y, Tham K, Sekhar S, Wong N, et al. Thermal comfort study of an air-conditioned lecture theatre in the tropics. Building and Environment. 2003;38:63-73.

[7] Suárez MJ, Gutiérrez AJ, Pistono J, Blanco E. CFD analysis of heat collection in a glazed gallery. Energy and Buildings. 2011;43:108-16.

[8] Carlos JS, Corvacho H, Silva PD, Castro-Gomes J. Modelling and simulation of a ventilated double window. Applied Thermal Engineering. 2011;31:93-102.

[9] Ismail KA, Salinas CT, Henriquez JR. A comparative study of naturally ventilated and gas filled windows for hot climates. Energy Conversion and Management. 2009;50:1691-703.

[10] Pal S, Roy B, Neogi S. Heat transfer modelling on windows and glazing under the exposure of solar radiation. Energy and Buildings. 2009;41:654-61.

[11] Yongson O, Badruddin IA, Zainal Z, Narayana PA. Airflow analysis in an air conditioning room. Building and Environment. 2007;42:1531-7.

[12] Al-Sanea SA, Zedan M, Al-Harbi M. Heat transfer characteristics in airconditioned rooms using mixing air-distribution system under mixed convection conditions. International Journal of Thermal Sciences. 2012;59:247-59.

[13] Murakami S, Kato S, Nakagawa H. Numerical prediction of horizontal nonisothermal 3-D jet in room based on the k- $\varepsilon$ model. ASHRAE Transactions. 1991;97.

[14] Awbi HB, Nemri M. Scale effect in room airflow studies. Energy and Buildings. 1990;14:207-10.

[15] He J, Hoyano A. Measurement and simulation of the thermal environment in the built space under a membrane structure. Building and Environment. 2009;44:1119-27.

[16] Huang H, Ooka R, Kato S. Urban thermal environment measurements and numerical simulation for an actual complex urban area covering a large district heating and cooling system in summer. Atmospheric Environment. 2005;39:636275.

[17] Tanimoto J, Hagishima A, Chimklai P. An approach for coupled simulation of building thermal effects and urban climatology. Energy and Buildings. 2004;36:781-93.

[18] Zhai ZJ, Chen QY. Sensitivity analysis and application guides for integrated building energy and CFD simulation. Energy and buildings. 2006;38:1060-8.

[19] Li X, Yu Z, Zhao B, Li Y. Numerical analysis of outdoor thermal environment around buildings. Building and Environment. 2005;40:853-66.

[20] Kim T, Kato S, Murakami S. Indoor cooling/heating load analysis based on coupled simulation of convection, radiation and HVAC control. Building and Environment. 2001;36:901-8. 
[21] Vercammen H, Froment G. An improved zone method using Monte Carlo techniques for the simulation of radiation in industrial furnaces. International Journal of Heat and Mass Transfer. 1980;23:329-37.

[22] Howell JR. Application of Monte Carlo to heat transfer problems. Advances in Heat Transfer. 1968;5:1-54.

[23] Corlett R. Direct Monte Carlo calculation of radiative heat transfer in vacuum. Journal of Heat Transfer. 1966;88:376-82.

[24] Toor J, Viskanta R. A numerical experiment of radiant heat interchange by the Monte Carlo method. International Journal of Heat and Mass Transfer. 1968;11:883-97.

[25] Burgess D, Hertzberg M, Afgan N, Beer J. Heat transfer in flames. Scripta Book Co. 1974:413.

[26] Holman J. Heat transfer 9th Edition. New York, Boston, McGraw-Hill, Inc. 2002:168-9.

[27] Su M, Chen Q, Chiang C-M. Comparison of different subgrid-scale models of large eddy simulation for indoor airflow modeling. Journal of Fluids Engineering. 2001;123:628-39.

[28] Hong K, Hong T-K, Yang H-S. Thermal conductivity of Fe nanofluids depending on the cluster size of nanoparticles. Applied Physics Letters. 2006;88:031901.

[29] Oberkampf WL, Barone MF. Measures of agreement between computation and experiment: validation metrics. Journal of Computational Physics. 2006;217:536.

[30] Guide C. Thermal properties of building structures (A3). The Chartered Institution of Buildings Services, London. 1980.

[31] Pérez-Grande I, Meseguer J, Alonso G. Influence of glass properties on the performance of double-glazed facades. Applied Thermal Engineering. 2005;25:3163-75.

[32] Manz H. Total solar energy transmittance of glass double façades with free convection. Energy and buildings. 2004;36:127-36.

[33] Hamza N. Double versus single skin facades in hot arid areas. Energy and Buildings. 2008;40:240-8.

[34] Larsen SF, Rengifo L, Filippín C. Double skin glazed façades in sunny mediterranean climates. Energy and Buildings. 2015.

$\begin{array}{ll}\text { Nomenclature } \\ N & \text { Number of hexahedron cells } \\ a & \text { Grid spacing } \\ n & \text { Number of nodes } \\ \rho & \text { Density of fluid } \\ t & \text { Time } \\ u & \text { Velocity magnitude in x direction } \\ v & \text { Velocity magnitude in y direction } \\ w & \text { Velocity magnitude in z direction } \\ \tau & \text { Shear stress } \\ \mathrm{P} & \text { Pressure } \\ e & \text { Internal energy } \\ k & \text { Turbulent kinetic energy } \\ \varepsilon & \text { Rate of dissipation } \\ \mu_{\mathrm{t}} & \text { Turbulent viscosity }\end{array}$


$\mathrm{G}_{\mathrm{k}} \quad$ Generation of turbulent kinetic energy resulting from mean velocity gradients

I Number of iterations

$\mathrm{C}_{1 \varepsilon}, \mathrm{C}_{2 \varepsilon}, \mathrm{C}_{3 \varepsilon} \quad$ Constants used in turbulent model

$\sigma_{\mathrm{k}}$

Turbulent Prandtl numbers for $k$

$\sigma_{\mathrm{E}}$

Turbulent Prandtl numbers for e

$E$

Total energy

$\left(\tau_{\mathrm{ij}}\right)_{\mathrm{eff}}$

Deviatory stress tensor

$T$

Temperature

$\mathrm{c}_{\mathrm{p}}$

Specific heat capacity at constant pressure

$\mathrm{C}_{\mathrm{ij}}$

Convection term in Reynolds stress

Transportation equation

$\mathrm{D}_{\mathrm{ij}}^{\mathrm{T}}$

Turbulent diffusion term in Reynolds stress

Transportation equation (RSTE)

$D_{i j}^{L}$

Molecular diffusion term in RSTE

$P_{i j}$

Stress production term in RSTE

$G_{i j}$

Buoyancy production term in RSTE

$\emptyset_{\mathrm{ij}}$

Pressure strain term in RSTE

$\varepsilon_{\mathrm{ij}}$

Dissipation term in RSTE

$\mathrm{F}_{\mathrm{ij}}$

Production by system rotation term in RSTE

$\mu$

Dynamic viscosity compressible

$\operatorname{Pr}_{1}$

Prandtl number 